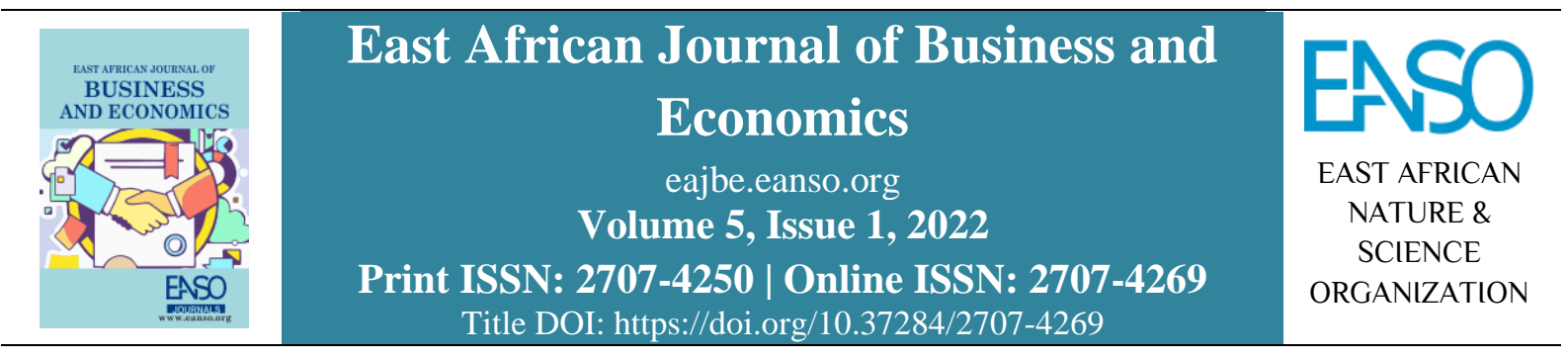

Original Article

\title{
Effect of Covid-19 Pandemic on the Weekly Stock Prices of Financial Institutions: A Comparison of East African Security Markets.
}

\author{
Dr. Janeth Patrick Swai, $P h D^{1}$ \& Ibrahim Magwana Ngollo, $P h D^{2 *}$ \\ ${ }^{1}$ Mzumbe University Dar es salaam College Campus, P.O.Box 20266, Dar es salaam, Tanzania. \\ ${ }^{2}$ College of Business Education Mbeya campus, P. O. Box 3810, Mbeya, Tanzania. \\ * ORCID: https://orcid.org/0000-0003-0223-5527; Correspondence email: magwanaibrahim@gmail.com.
}

Article DOI: https://doi.org/10.37284/eajbe.5.1.531

\section{Date Published: ABSTRACT}

17 January 2022 This study aimed at comparing the effect of the COVID-19 pandemic on the weekly stock prices of financial institutions registered among the East

Keywords: African securities markets (EAC). The study employed a descriptive research design. The findings suggest that stock prices were negatively

COVID-19 Pandemic, Weekly Stock Prices, Financial Institutions, Rational Expectation, Behavioural Finance. affected by the COVID-19 pandemic. Weekly closing prices during the COVID-19 pandemic was significantly different from the weekly stock prices of the period before the pandemic. The comparison showed that during the pandemic, the difference in weekly stock prices was significant between Tanzania and Kenya as well as Uganda and Kenya. Uganda suffered the worst effect of the COVID pandemic. The fluctuations in weekly stock prices were higher before the pandemic period as compared to the pandemic period. The t-test concluded that those changes in fluctuation were statistically significant for the EAC bloc except for Tanzania. The researchers recommend that institutions governing the economy in which the stock markets operate adhere to the objective truth during times of crisis such as the COVID-19 pandemic.

\section{APA CITATION}

Swai, J. P., \& Ngollo, I. M. (2022). Effect of Covid-19 Pandemic on the Weekly Stock Prices of Financial Institutions: A Comparison of East African Security Markets. East African Journal of Business and Economics, 5(1), 20-34. https://doi.org/10.37284/eajbe.5.1.531

\section{CHICAGO CITATION}

Swai, Janeth Patrick, and Ibrahim Magwana Ngollo. 2022. "Effect of Covid-19 Pandemic on the Weekly Stock Prices of Financial Institutions: A Comparison of East African Security Markets". East African Journal of Business and Economics 5 (1), 20-34. https://doi.org/10.37284/eajbe.5.1.531.

\section{HARVARD CITATION}

Swai, J. P., \& Ngollo, I. M. (2022) "Effect of Covid-19 Pandemic on the Weekly Stock Prices of Financial Institutions: A Comparison of East African Security Markets", East African Journal of Business and Economics, 5(1), pp. 20-34. doi: 10.37284/eajbe.5.1.531.

\section{IEEE CITATION}

J. P. Swai, \& I. M. Ngollo. "Effect of Covid-19 Pandemic on the Weekly Stock Prices of Financial Institutions: A Comparison of East African Security Markets", EAJBE, vol. 5, no. 1, pp. 20-34, Jan. 2022.

20 | This work is licensed under a Creative Commons Attribution 4.0 International License. 


\section{MLA CITATION}

Swai, Janeth Patrick, and Ibrahim Magwana Ngollo. "Effect of Covid-19 Pandemic on the Weekly Stock Prices of Financial Institutions: A Comparison of East African Security Markets". East African Journal of Business and Economics, Vol. 5, no. 1, Jan. 2022, pp. 20-34, doi:10.37284/eajbe.51.531

\section{INTRODUCTION}

Throughout the years, financial institutions (FI) have played a major role in the conduct of commerce and trade across the globe. According to Alfieri (2021), FI performs a number of vital roles, including providing working capital to support international trade transfers and reducing payment risks. With regards to FI vitality expressed above, it is likely for an investor to place their monies in their shares.

When an investor buys stocks of the financial institutions, he /she expects to obtain dividends and capital gains arising from positive price changes (Defrizal et al., 2021). Prices of stocks and shares can be influenced by major events such as COVID-19 which may cause panic in the stock markets. Studies conducted in other countries indicate that the pandemic affected the stock prices of various companies (Griffith et al., 2020; Dani et al., 2020). However, there was a contextual exception and the dilemma of outlook and perception on the pandemic in the East African countries (EAC) where governments opted for different approaches in tackling the pandemic.

Such circumstance presented a rare opportunity to compare the results of analysis between the countries belonging to the same economic bloc and region, sharing similar characteristics but having a different outlook on the disease and thus brought novelty to this study. Such an opportunity enables the study to contribute to the existing body of knowledge by providing information on the different reactions of the stock prices of financial institutions towards differences in outlook, approaches and methods employed by the governing authorities in the East African community during the pandemic. Such information will enable investors and policymakers to make better decisions in the future in case a pandemic or other disaster occurs again. The study focused on the financial institutions due to their economic significance and their large dependence on the movement of capital, assets, and liquidity which was significantly reduced during the COVID-19 pandemic, as stated by Malini (2020).

This study aimed at comparing the effects of the COVID-19 pandemic on the weekly stock price movement of financial institutions listed in the East Africa securities exchanges and specifically aimed at providing answers to two research questions:

- Was there any similarity in the extent of fluctuations of financial institutions' weekly stock prices before and during the COVID-19 pandemic in EAC?

- Which country suffered the worst effect of the COVID-19 pandemic on the weekly stock price fluctuations of the financial institutions in the EAC?

\section{LITERATURE REVIEW}

\section{Classical vs Behavioural Finance theory}

The efficient market hypothesis states that the market is efficient at all times, share prices reflect all the available information and that it is difficult to beat or achieve the market above-average returns on a sustainable basis (Fama \& Malkiel, 1970). If that is the case, then the share prices during the COVID-19 pandemic are likely to act as a good indicator of the information and circumstances regarding the market with optimism profound in shares whose prices are climbing and doom and gloom overshadowing the shares whose prices are falling.

However, Zhang (2018) ponders that the main drawback of the classical financial theories, such as the efficient market hypothesis, is that they ignore the role played by irrationality in the financial markets. Irrationality problem arises when the prices of the asset fail to reflect the values assigned by considering fundamental 
analysis which has incorporated all the possible information available to the analyst.

The behavioural finance theory attempts to bridge the irrationality gap by taking into consideration investors' feelings, attitudes, other psychological factors and market inefficiencies within its framework (Sharma \& Kumar, 2019). Phuong (2021) employed the behavioural finance theory to explain his results when he examined how the COVID-19 pandemic affected the share price of the Vietnam Oil and Gas industry

\section{Rational Expectation theory}

The rational expectation theory states that individuals base their decisions on three factors, namely human rationality, their past experience and information available to them (Muth, 1961). The rational expectations hypothesis asserts three things, (i) information is scarce and the economic system does not put it to waste; (ii) the way expectations are formed rely on the structure of the relevant system describing the economy and (iii) public prediction will not have any substantial effects on the operations of the economic system. If the rational theory is to hold true, then the outcomes of expectation between investors from different countries ought to be different. The process of framing expectations is highly subjective with reference to different circumstances, perceptions and regulatory systems. It is likely for investors perception of the future profits and risks during the COVID-19 pandemic to have been different among the countries and such differences might be observed in the movement of the weekly stock prices. Polemis and Soursou (2020) used the theory to assess the Impact of the COVID-19 Pandemic on the Greek Energy firms.

\section{Empirical Review}

Arendt and Mestas (2021) determined that there was a positive relationship between the amount of news coverage about COVID-19 and the extent of the stock price drop among the leading 58 indices across the globe. He et al. (2020) studied the Chinese stock market and concluded that transportations, mining, electricity and heating, and environmental industries had been adversely impacted by the pandemic. However, manufacturing, information technology, educations and healthcare industries have been resilient to the pandemic. Rajamohan et al. (2020) examined the impact of COVID-19 on stock prices of NSE India in the automobile sector. The results showed that there was a significant impact of automobile sector index price movements after the COVID - 19 in India. Höhler and Lansink (2020) measured the impact of the COVID-19 pandemic by analysing the stock price reactions of 71 major listed companies in the food value chain in four different phases of the pandemic in the US, Japan, and Europe. They found out that the stock prices of manufacturers of fertilisers and agrochemicals, as well as food distributors, displayed high volatility while stock prices of food retailers displayed low volatility.

Griffith et al. (2020) assessed the Impact of COVID-19 on Share Prices in the UK. the findings showed that the FTSE All-Share price index saw a sharp decline in the weeks following the announcement of a lockdown in Northern Italy and fell to its lowest point in the week following the announcement of social distancing in the UK (down 35\% from the start of January). They also found out that the industries that were hardest hit during the pandemic were tourism and leisure (which includes air travel), fossil fuels production and distribution, insurance, retailers (excluding food and drug retailers) and some large manufacturing industries. However, they also noted that certain industries outperformed the market including food and drug manufacturers and retailers, utilities, high tech manufacturing and tobacco. Firms in medical and biotech research provided a surprise by outperforming the market (increasing by $6 \%$ compared to the overall decline of $21 \%$ ).

Ghulam et al. (2020) conducted a study in Indonesia where they examined the Stock Market Reaction to COVID-19 in the consumer goods sector using an event study approach. Findings indicated a significant difference between the 
daily closing stock price and volume of stock trade before and after the COVID-19 pandemic. Miati and Pertama (2020) analysed market reactions before and after the announcement of the COVID-19 pandemic virus by using the composite stock price index from companies listed on the Indonesia Stock Exchange (IDX) in 2020. The result showed that there was a difference in composite stock price index data before and after the announcement of the COVID19 pandemic.

Hutauruk (2020) examined the before and aftereffects of the COVID-19 pandemic phenomenon on the IDX composite in Indonesia. The findings indicated that there was a significant difference between the averages and variances in the composite price index before the pandemic and after the pandemic. Hamza et al. (2020) carried out a comparative study by assessing the impact of the pandemic on pharmaceutical sectors across the globe. They analysed the indices of 3 countries that were similarly hit, i.e., the UK, USA and India. The findings indicated that indices of impacted countries showed different reactions to the announcements. None of the countries showed any significant similarity among themselves with respect to the indices.

Findings from the above literature cannot be generalised to every other part of the world. Attempting to look at the stock price reactions during the pandemic and com-paring countries without taking into context the approaches taken by the respective countries might fail to highlight the potentials or failures of strategic choices taken by governing authorities in combating COVID19. This study fills that gap by comparing countries that had different approaches towards dealing with COVID-19 and thus brings into view the outcomes in association with the approaches taken.

\section{RESEARCH METHODOLOGY}

This study employed a descriptive research design. The study was carried out in East Africa by focusing mainly on Tanzania, Kenya and Uganda. Rwanda, South Sudan and Burundi were excluded due to their infancy in the stock exchange markets. The population involved were 44 financial institutions; there was no sampling, all the FI were studied.

The study used secondary data which were collected for 24 weeks before the pandemic starting August 2019 and 24 weeks during the pandemic beginning on February 72020. February 72020 was selected as a commencement of the COVID-19 pandemic since WHO formally declared the novel coronavirus outbreak a public health emergency of international concern (PHEIC) on January 312020 (WHO, 2021). Weekly data on stock prices were obtained from the respective countries securities exchange market website and https://www.investing.com/equities/.Weekly exchange rates were obtained from the central bank websites of the respective countries.

Analysis of data was done after all the share prices were converted to United States dollars to facilitate comparison. For the purpose of evaluating the extent of fluctuations of financial institutions' weekly stock prices among East African security markets (EAC), descriptive statistics and graphical analysis was used. Movement of the stock price was measured by the weekly rate of change expressed in percentage, as shown in the formula below:

$$
\begin{aligned}
& \text { Movement of the stock price } \\
& =\frac{\text { closing price }- \text { opening price }}{\text { closing price }} \times 100
\end{aligned}
$$


To examine whether there was any similarity in the movements of weekly stock prices of financial institutions between the pre-COVID-19 pandemic

\section{FINDINGS}

period and during the COVID-19 pandemic period, the T-test was employed.

Table 1: Descriptive statistics of the FI stock price and weekly rate of change of the stock price of FI in EAC

\begin{tabular}{|c|c|c|c|c|c|c|c|c|c|}
\hline \multicolumn{5}{|c|}{ Weekly stock price of financial institutions } & \multicolumn{5}{|c|}{ Weekly rate of change of stock price of financial institutions } \\
\hline & EAC & Tanzania & Kenya & Uganda & & EAC & Tanzania & Kenya & Uganda \\
\hline \multicolumn{5}{|l|}{ Before Covid-19 } & \multicolumn{5}{|l|}{ Before Covid-19 } \\
\hline Mean & 0.84 & 0.58 & 1.05 & 0.61 & Mean & $0.16 \%$ & $0.09 \%$ & $0.19 \%$ & $0.21 \%$ \\
\hline Standard deviation & 0.02 & 0.01 & 0.02 & 0.02 & Standard deviation & $1.11 \%$ & $3.43 \%$ & $1.21 \%$ & $2.56 \%$ \\
\hline Coefficient of variation & $2 \%$ & $2 \%$ & $2 \%$ & $4 \%$ & Coefficient of variation & $685 \%$ & $3778 \%$ & $624 \%$ & $1206 \%$ \\
\hline Minimum & 0.81 & 0.55 & 1.00 & 0.56 & Minimum & $-2 \%$ & $-13 \%$ & $-2 \%$ & $-7 \%$ \\
\hline Maximum & 0.87 & 0.63 & 1.09 & 0.64 & Maximum & $2 \%$ & $8 \%$ & $3 \%$ & $5 \%$ \\
\hline Observation count & 24 & 24 & 24 & 24 & Observation count & 23 & 23 & 23 & 23 \\
\hline \multicolumn{5}{|l|}{ During Covid-19 } & \multicolumn{5}{|l|}{ During Covid-19 } \\
\hline Mean & 0.75 & 0.50 & 0.97 & 0.49 & Mean & $-0.85 \%$ & $-1.02 \%$ & $-0.58 \%$ & $-1.81 \%$ \\
\hline Standard deviation & 0.05 & 0.05 & 0.04 & 0.07 & Standard deviation & $1.78 \%$ & $2.70 \%$ & $1.49 \%$ & $4.39 \%$ \\
\hline Coefficient of variation & $6 \%$ & $9 \%$ & $4 \%$ & $15 \%$ & Coefficient of variation & $-210.52 \%$ & $-266.13 \%$ & $-256.28 \%$ & $-242.95 \%$ \\
\hline Minimum & 0.69 & 0.45 & 0.90 & 0.40 & Minimum & $-6 \%$ & $-9 \%$ & $-4 \%$ & $-13 \%$ \\
\hline Maximum & 0.84 & 0.59 & 1.05 & 0.63 & Maximum & $3 \%$ & $4 \%$ & $2 \%$ & $5 \%$ \\
\hline Observation count & 24 & 24 & 24 & 24 & Observation count & 23 & 23 & 23 & 23 \\
\hline
\end{tabular}

Source: prepared by researchers from data of the weekly closing prices of financial institutions listed at the three EAC Stock Exchanges 
The result from Table 1 above indicates that the presence of the COVID-19 pandemic led to a decline in the weekly stock prices of the FI in the EAC. Uganda observed the largest price drop as the average price fell by $20.13 \%$ from USD 0.61 before the pandemic to USD 0.49 during the pandemic, followed by Tanzania, where average prices fell by $13.81 \%$ and Kenya with a fall of $7.76 \%$.

The standard deviation and coefficient of variation (COEV) also indicate that the drop in prices was more pronounced during the pandemic as compared to before the pandemic period. COEV in Tanzania and Uganda quadrupled from $4 \%$ to $15 \%$ in Uganda and from $2 \%$ to $9 \%$ in Tanzania.
The average rate of change of weekly stock price was positive before the pandemic indicating that the prices were trending upward; the largest average rate of change was observed in Uganda at $0.21 \%$, while the lowest average rate of change was observed in Tanzania at $0.09 \%$. The negative average rate of change observed during the pandemic further cement the fact that prices were falling at an average weekly rate of $1.81 \%, 1.02 \%$, $0.58 \%$ and $0.85 \%$ in Uganda, Tanzania, Kenya and the EAC bloc, respectively.

COEV of the rate of change of weekly stock prices were higher before the pandemic period indicating high variability in the rate of weekly price fluctuations before the pandemic as compared to the pandemic period.

Table 2: EAC financial institutions t-Test for weekly closing prices and weekly rate of change in stock prices before the COVID-19 pandemic

\begin{tabular}{llll}
\hline & & T & Sig (2 tailed) \\
\hline \multirow{2}{*}{ Weekly closing price } & Uganda WCPDP - Uganda WCPBP & -6.800 & 0.00 \\
& Tanzania WCPDP - Tanzania WCPBP & -8.341 & 0.00 \\
& Kenya WCPDP - Kenya WCPBP & -6.876 & 0.00 \\
& EAC WCPDP - EAC WCPBP & -7.181 & 0.00 \\
& Uganda WCPDP - Tanzania WCPDP & -1.542 & 0.14 \\
& Uganda WCPDP - Kenya WCPDP & -55.634 & 0.00 \\
& Tanzania WCPDP - Kenya WCPDP & -141.201 & 0.00 \\
\hline Weekly rate of change & Uganda RWCPDP - Uganda RCWPBP & -2.102 & 0.05 \\
in stock prices & Tanzania RWCPDP - Tanzania RCWPBP & -1.216 & 0.24 \\
& Kenya RWCPDP - Kenya RCWPBP & -2.246 & 0.04 \\
& EAC RWCPDP - EAC RCWPBP & -2.300 & 0.03 \\
\hline
\end{tabular}

Key: $W C P D P=$ weekly stock prices during the pandemic; $W C P B P=$ weekly stock prices before the pandemic

Source: Prepared by the researchers with data from the weekly closing prices of financial institutions listed at the three EAC Stock Exchanges with results obtained from Ms Excel

From Table 2 above, the t-test indicates that the average weekly stock prices during the pandemic (WCPDP) were significantly different from the average weekly stock prices before the pandemic period (WCPBP). Presence of the COVID-19 pandemic affected the weekly stock prices of the FI in EAC. Results are in line with the results of Yunus and Uslu (2020) who found that banking and insurance sector in-dices were affected by COVID19, (Machmuddah et al., 2020) who determined that a significant effect existed between COVID-19 and stock prices of the customer goods sector in Indonesia, (Ramelli \& Wagner, 2020) who 
concluded that there was a positive and significant effect between COVID-19 and stock price transactions and stock trade volume.

The results observed above are in line with both rational expectation theory and behavioural finance theory. Perception of the future will always be influenced by the matters that pertain today. Wachter (2020) lays it out by pondering that the security markets are forward-looking and they anticipated the wreckage caused by the current COVID-19 pandemic with steep declines at the end of February. Dealers in the market are individuals with sentiments, the behavioural finance theory contends that rare events and pandemics are likely to influence those sentiments and investors psyche which will ultimately be reflected in the stock prices.

The results above can be further be signified by looking at Figure 1 below which presents a graphical presentation of the weekly stock prices during the pandemic and before the pandemic, both overlaid in a single graph to facilitate comparison.

Figure 1: Graphical comparison of the average weekly closing prices before and during the COVID19 pandemic in the $\mathrm{EAC}$

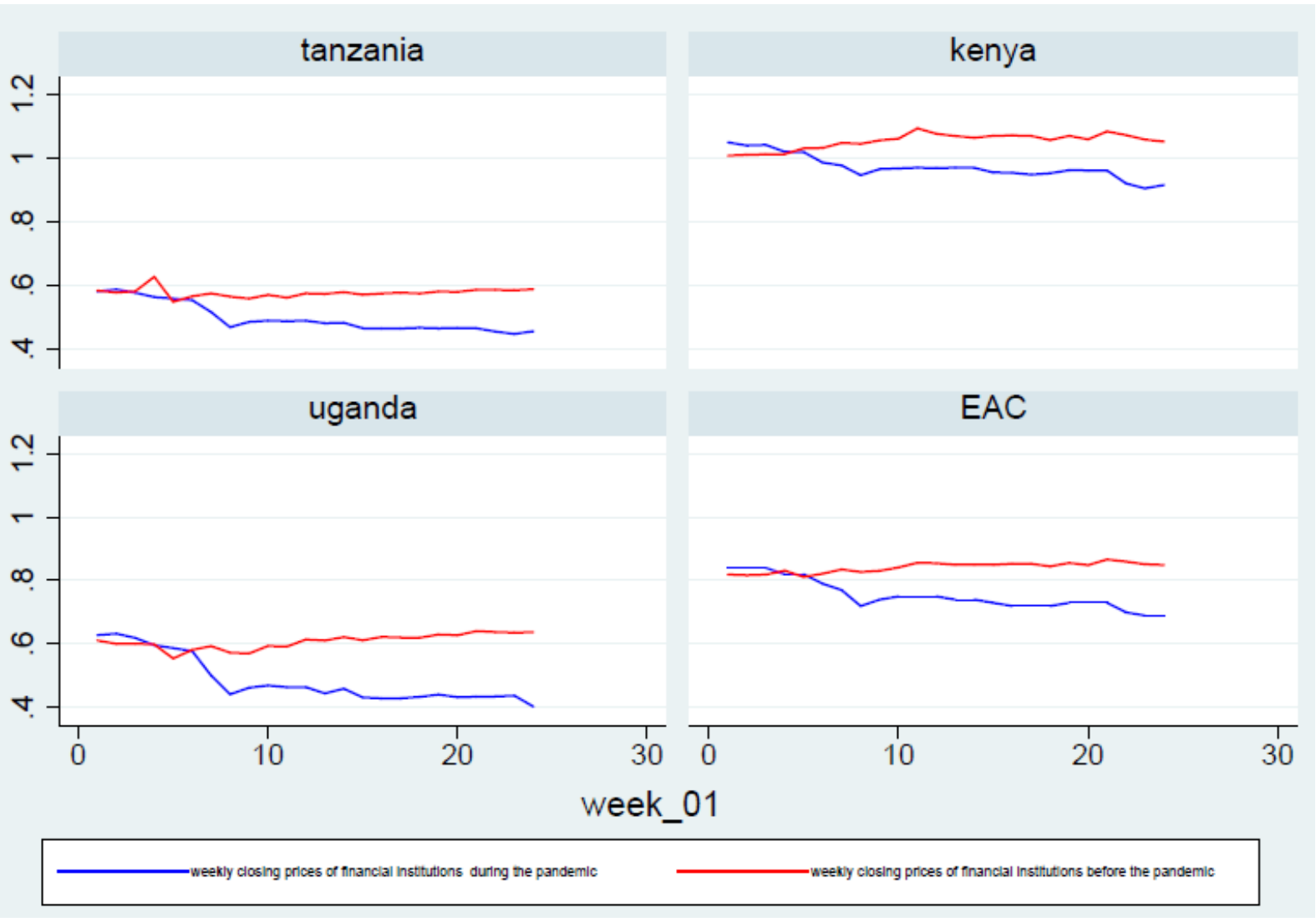

Source: Prepared by researchers with data from the weekly closing prices of financial institutions listed at EAC Stock Exchanges. The red line presents stock prices before the pandemic and the blue line presents the stock prices during the pandemic.
From Figure 1 above, it can clearly be seen that the weekly closing prices before the pandemic (shown in red colour) were steadily trending upward, while the weekly closing prices during the pandemic (shown in blue colour) were steadily trending downwards. The pandemic caused a price drop in all three countries and the EAC bloc as a whole.

26 This work is licensed under a Creative Commons Attribution 4.0 International License. 
The comparison of the weekly rate of price change during the pandemic (RWCPDP) and the weekly rate of the price change before the pandemic (RCWPBP) show that price fluctuation was different between the pandemic period and before the pandemic period only in Kenya and Uganda. The T-test signifies that volatility in weekly prices in the Tanzania market was not significantly different between the pandemic period and before the pandemic period

Höhler and Lansink (2020) also came with a similar result for the stock prices of food retailers, which they observed that had displayed low price volatility during the pandemic, but they also contradictorily observed that the majority of the stock markets reacted to the pandemic with an increased level of price volatility. Ibrahim and Kamaludin (2020) also came out with mixed results in which they found out that all the stock markets of the sampled countries they studied, except Japan, experienced very low or low volatility over the short-term horizons during the pandemic. They also found that in contrast, Vietnam, Malaysia, and Laos experienced medium volatility over the medium-term horizons and finally, they determined that China, Japan, South Korea, Malaysia, and the Philippines experienced high volatility over the long-term horizons.

Figure 2 below gives a visual perspective of the weekly price fluctuations experienced during both the pandemic period and before the pandemic period

Figure 2: Graphical comparison of the rate of change of average weekly closing prices before and during the COVID-19 pandemic

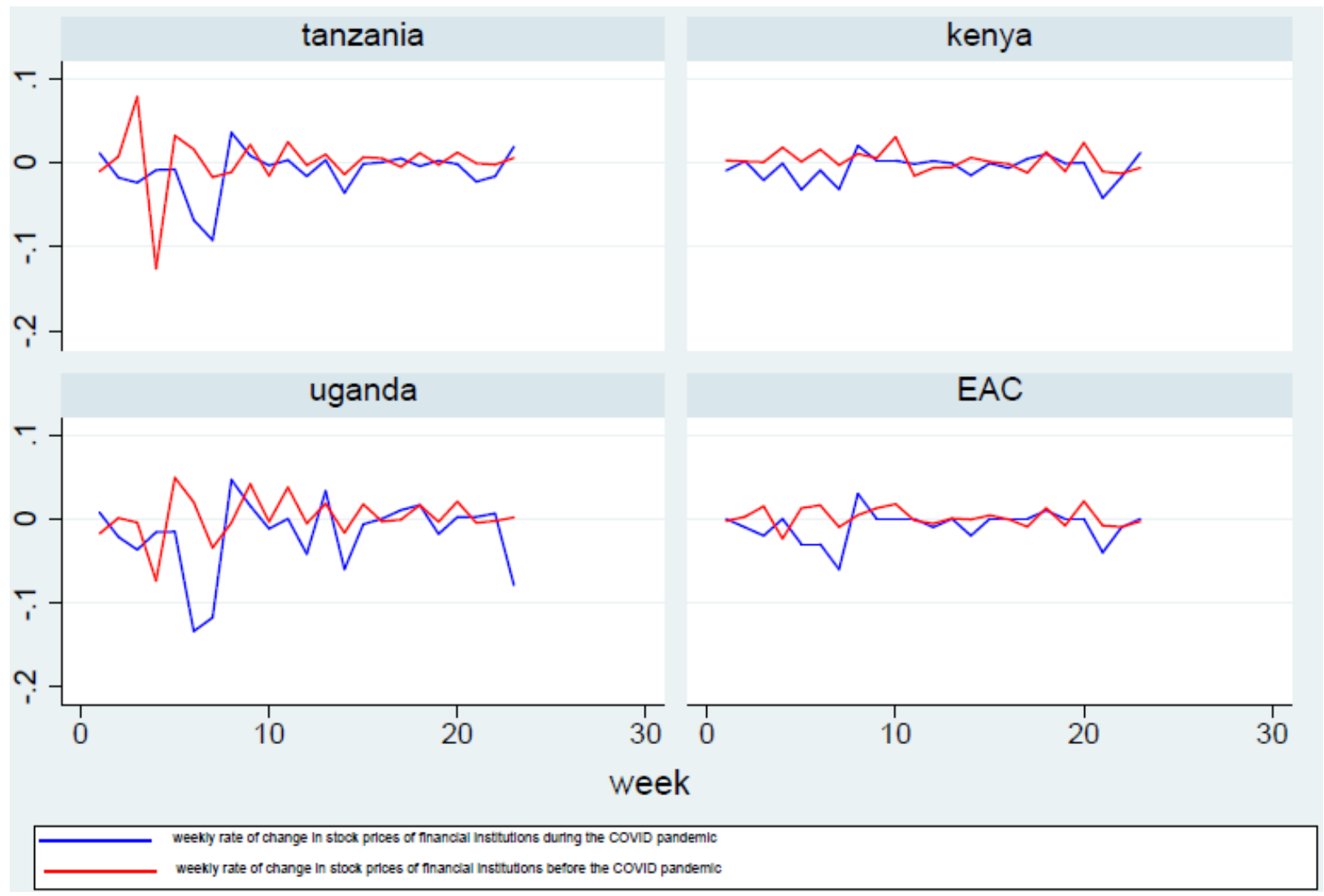

27 | This work is licensed under a Creative Commons Attribution 4.0 International License. 
Source: researchers with data from the weekly closing prices of financial institutions listed at EAC Stock Exchanges. The blue line presents the weekly rate

Of note are the spikes observed from week six to week eight during the pandemic where there was a significant rate of change in prices in Tanzania and Uganda, with a little shift observed in Kenya as prices fell and climbed up again before stabilising for the remaining weeks during the study. Such volatility could be the result of events that unfolded during those weeks as described below.

The first case of COVID-19 in east Africa was reported in Kenya on March 122020 which was in the $6^{\text {th }}$ week during the pandemic period in this study. Tanzania reported its first COVID-19 case on March 162020 which was the $7^{\text {th }}$ week during the pandemic period, while Uganda reported its first COVID-19 case on March 21 2020, which was the $8^{\text {th }}$ week during the pandemic period. The high volatilities seen in the graphs during the period from $6^{\text {th }}$ to $8^{\text {th }}$ weeks might be due to the market adjusting to the realities that COVID-19 now was in their front doors and they would somehow have to deal with it. This phenomenon is similar to findings by (Ashraf, 2020) who observed that the stock markets responded strongly in the early days of confirmed COVID-19 cases and the reactions that the market produced varied over time depending on the phase of the outbreak of the pandemic.

\section{DISCUSSION OF THE FINDINGS}

The analysis determined that the weekly stock prices of financial institutions in EAC during the pandemic were slightly falling and trending downward as compared to the before the pandemic period in which they were rising and trending upward. The T-test also confirmed that the level of price change during the pandemic was significantly different from the level of price changes observed before the pandemic.
The findings are concurrent to the findings of Rajamohan et al. (2020), the data from their study showed that there was a significant impact of COVID-19 on Price movements of automobile sector index stock price. The findings are also in line with Höhler and Lansink (2020) who observed that the pandemic had a different effect on different sectors. While it caused higher price volatilities in some sectors, it also resulted in low stock price volatilities in other sectors as well. They further contended that the effects of COVID-19 are subsector-specific. Each sector will be differently affected from other sectors. In the case of the financial institutions in EAC, they were negatively affected by the pandemic.

These results coupled with results from other studies presented above signifies further the rational expectation theory. Investors are more likely to form different expectations for different sectors depending on the prevailing circumstances. For investors with shares in the FI, the concern would have been high on the lack of liquidity which was probably going to arise as a result of the economic downturn caused by the pandemic and thus, they would not be expecting good returns during the pandemic.

Looking back at the low level of price shifts during the pandemic in EAC, the researchers believe that they might be attributed to low trading volume caused by the fears which investors might have developed due to the uncertainty brought by the pandemic. It could be that buyers were no longer willing to buy even if the sellers were willing to sell, or it could be that investors might have opted to hold on to certain stocks, especially those that were likely to pay dividends leaving the market with depressed demand and supply.

Another reason could be the decline in economic activities brought as a result of the pandemic. Since there were restrictions of movement in Kenya and Uganda, the state of concern was higher in Tanzania even though the governing institutions tried their 
level best to remove the fear from the citizens and take on the business-as-usual approach. It is fair to state that individuals were more inclined towards staying safe whenever it was possible rather than going out and carrying on with economic activities even though there were no restrictions. However, the T-test indicates the differences. In price fluctuation during the pandemic and before the pandemic was insignificant in Tanzania, perhaps we can argue that the approach taken by the governing authority in Tanzania might have contributed to the occurrence of such findings. As Buguzi (2021) writes that the governing institutions in Tanzania halted the publication and release of COVID data stating the reason being that such release of data was fuelling public panic and decided to turn to GOD for prayers.

No matter how mediocre that might sound, one cannot deny how the human psyche is affected and influenced by such confidently placed religious stances. When a high level of confidence is instilled inside the human being, positive performance is likely to occur. According to Yuliani et al. (2017), the way investors perceive risk and their psychological composition significantly affect their confidence. From such a perspective, we might be tempted to say the approach which was taken by the Tanzanian government, no matter how awkward it may now seem, did assist in reducing panic among the investors in the DSE and thus resulting in price fluctuations that were not significantly different during the pandemic and before the pandemic.

Kenya and Uganda chose to strictly deal with the pandemic up to the level at which they imposed a lockdown on their citizens. The decline in economic activities from such measures was likely to curb the movement of money among individuals. With no money to move around, there is less chance of having high price fluctuations as the buyers have less monetary power to influence the market. Bloom (2014) suggests that during a period of uncertainty, there is a reduction in willingness to invest and spend.
Descriptive statistics determined that Uganda suffered the worst effect of the COVID-19 pandemic on the weekly stock prices of financial institutions. Uganda suffered the largest average price drop of $20 \%$ and the highest rate of weekly price changes of $-1.81 \%$. However, comparative statistics displayed that Uganda and Tanzania behaved as if they came from a similar distribution. From the T-test, the average prices were not significantly different between financial institutions in Tanzania and Uganda.

The similarity of the severity of the effects of the COVID pandemic on Tanzania and Uganda might be an indication of the validity of the rational expectation theory. The theory deliberates that the way expectations are formed relies on the structure of the relevant system describing the economy. Kenya was the only country in East Africa which had a head start in preparing for the pandemic as soon as the news of it started to circulate. According to Hillier et al. (2020), Kenya produced its first COVID-19 preparedness plan in December 2019. They further note that Uganda did not have an available response plan. From the researchers' observation, Tanzania did not have a publicly available COVID preparedness and response plan.

Hillier et al. (2020) also pondered that to have an effective response and preparedness to the pandemic requires an up-to-date legal framework that was in place in Kenya. The researchers believe that such early response, preparedness and openness of information separated Kenya from Tanzania and Uganda and led to the country suffering the least effect of the COVID-19 pandemic in the East African bloc.

The observation above concurs with both the behavioural aspects of finance and the rational expectation theory. From the behavioural finance, the researchers contend that the market in Kenya was much at ease due to the assurance they obtained from the government by putting an early response 
plan even before the disease was declared a pandemic by WHO.

Every et al. (2018) denotes that notion of preparedness is paramount in influencing and moderating behaviour. Psychologically prepared individuals are more likely to obtain a general understanding of how an emergency situation might 'behave' and the risks that it might bring along. Such individuals are more likely to anticipate how they can cope with such threats and be able to ward off negative thoughts. When an individual is psychologically prepared, he/she is more likely to develop greater confidence in adapting to the changing conditions. As put forward by Every et al. (2018) above, the researchers are also of the opinion that it was likely for psychological panic to be less in Kenya as the country was publicly aware of the possibilities of the oncoming deadly disease and the plan in hand to deal with it was available for everyone to see. Tanzania and Uganda's failure to put in place an effective plan addressing what was to be done led to psychological panic.

On the other hand, Bloom (2014) contend that public policy that is unclear, hyperactive or both may raise uncertainty and that the level of development may lead a country to be more susceptible to natural disasters like epidemics and floods. Looking at the argument of the level of development and susceptibility to natural disasters also seem plausible to explain why Uganda suffered the worst effect, followed by Tanzania and Kenya. Kenya is the largest and more developed economy in East Africa; thus, it is more likely that it suffered the least effect of COVID-19 due to the ability of its massive economy to withstand the COVID shock, as stated by Bloom (2014) above.

The researchers are of the opinion that the authorities in Tanzania also looked at the matter in the same mirror placed by (Bloom, 2014). The greatest question was on whether the Tanzanian economy is able to withstand the COVID-19 shock and walk out with minor effect if the country was to follow all the anti-COVID-19 protocols? Looking at the matter from that perspective, it becomes easier to understand why the country could not afford to impose strict anti-COVID-19 measures. The economy was not gigantic enough or attuned to the state of limiting the movement of individuals and traders. Imposing a lockdown and strict social distancing measures would have been detrimental to the Tanzanian economy.

Another argument for countries from a similar economic bloc to suffer different effects of COVID19 is put forward by Fernandez-Perez et al. (2021), who determined that the magnitude of the stock market response differs depending on the country cultural values. According to them, countries with higher individualism scores suffered less stock market decline than countries with lower individualism scores by the end of week three since the first infection case announcement. It could be that Tanzania and Uganda are less individualistic societies as compared to Kenya. The researchers can only make an argument on this matter basing only on personal observation. Empirically all the three countries have a low individualism index of 25 which rank them as collective societies. Such low scores might be attributed to the manner and ways in which the majority of tribes in East Africa tend to live collectively. However, there are no tribes in the stock markets only ruthless investors in search of wealth and profits.

It is not easy to say that the collective spirit can exist among individuals who are seeking the highest possible gain in profit and wealth as the investors in the stock exchange markets. Given the idea that Kenya had a long-standing capitalistic economy and a very well matured stock exchange market, the researchers are of the opinion based on those grounds. There is a large chance for Kenya to be a more individualistic country when it comes to stock markets as investors have had a long time to experience and understand the viciousness and ruthlessness of the stock markets where only profit matters. Such kind of attitude is more likely to 
produce tenacious investors who can hold on strong and ride the violent tides such as the presence of the COVID-19 pandemic.

\section{CONCLUSION AND RECOMMENDATION}

For the first objective which aimed at comparing the extent of fluctuations of financial institution's weekly stock prices before and during the COVID19 pandemic in EAC, the researchers concluded that price fluctuations were large before the pandemic period as compared to the pandemic period and such differences were statistically significant as they were affirmed by the T-test which clearly confirmed that the level of price change during the pandemic was significantly different from the level of price changes observed before the pandemic

For the second objective which aimed at identifying the country which suffered the worst effect of the COVID-19 pandemic in the EAC on the weekly stock price fluctuations, the researchers conclude that Uganda suffered the worst effect of COVID-19 on the weekly stock price fluctuations.

In general, this study has shown that the COVID-19 pandemic negatively affected the weekly stock prices of FI; price drops were observed in all three countries of the EAC bloc. Tanzania and Uganda were more affected than Kenya in terms of the price drops and weekly price fluctuations. Perhaps this could be due to the openness with which institutions are run in Kenya as compared to Tanzania and Uganda. He et al. (2020) suggested that in the modern world, the stock market may be considered as the barometer of the economy. There are certain moments at which the stock market can effectively reflect the underlying economic and structural situation of a given country to a reasonable extent, and as observed in this study, the stock market did indeed put into full display the differences. In the structural situation between Tanzania, Kenya and Uganda.

The researchers recommend that institutions governing the economy in which the stock markets operate to adhere to the objective truth during times of crisis such as the COVID-19 pandemic. Furnishing appropriate and sufficient information issued objectively and in an open manner regarding such rare events may be helpful to investors and citizens at large. In a modern world, governing political institutions cannot afford to dig their heads in the sand or be operated based on personal or political truths when rare events such as the COVID-19 pandemic hit their country. In-formation sharing platforms are immense and free, individuals will seek out the information that is hidden from them and they will form speculations that may prove detrimental to the status of the economy as a whole and which could have been curtailed if the information was freely available.

The researchers further urge the investors to find out all the possible information before making investing decisions. Fear of anything is reduced when one's knowledge of its facts increases. Under such conditions of uncertainty of the future such as COVID-19 brought forth, it is better to rely on the fundamental and technical analysis and try best not to be motivated by emotions. Truth be told, no matter what we say in the end, we are all mortals and terminable, there are moments at which only courage can get one through tough times. Having the grits to bite on one's teeth a little bit longer and looking at all the information with equanimity might be an essential characteristic that should be strived for by stock market dealers to help them sail by the pandemics should they occur again.

Care should be taken when one wishes to generalise the results of this paper to the general population as there was a peculiar circumstance in east Africa that might not have necessarily existed in other parts of the world.

The researchers are of the opinion that further research should be done to assess the impact of the COVID-19 pandemic on the daily stock returns of financial institutions registered in east Africa. Future researchers can also develop models to 
assess the relationship between investors' sentiments and the daily stock prices of the financial institutions registered in then EAC.

\section{REFERENCES}

Alfieri, L. (2021). Heterogeneity of financial institutions in the process of economic and monetary integration in East Asia. World Economy, 44(4), 1053- 1076. https://doi.org/10 $.1111 /$ twec. 13029

Arendt, F., \& Mestas, M. (2021). Coronavirus Disease (COVID-19) Pandemic and Stock Price Crashes: A Cross-National Correlational Approach. Health Communication, 00(00), 1-8. https://doi.org/10.1080/10410236.2020.187116 8

Ashraf, B. N. (2020). Stock markets' reaction to COVID-19: Cases or fatalities? Research in International Business and Finance, 54. https://doi.org/10.1016/j.ribaf.2020.101249

Bloom, N. (2014). Fluctuations in uncertainty. Journal of Economic Perspectives, 28(2), 153-76.

Buguzi, S. (2021). Covid-19: Counting the cost of denial in Tanzania. The BMJ, 373, 1-2. https://doi.org/10.1136/bmj.n1052

Dani, A., Ainnurrochmah, A., \& Adrianingsih, N. (2020). Analysis for Evaluating the Impact of COVID-19 on the Indonesian Composite Stock Price Index. International Conference Labour Scientific Fair, 0-1.

Defrizal, D., Romli, K., Purnomo, A., \& Subing, H. A. (2021). A Sectoral Stock Investment Strategy Model in Indonesia Stock Exchange. Journal of Asian Finance, Economics and Business, 8(1), 015-022. https://doi.org/10.13106/jafeb.2021. vol8.no1.015

Every, D., Reynolds, A., Keen-Dyer, H., Dyer, M., Miller-Rose, P., \& Trigg, J. (2018). "That psychological bullshit": Surprising findings from community research are improving preparedness communication. Australian Journal of Emergency Management, 33(4), 5761.

Fama, E., \& Malkiel, B. G. (1970). Efficient Capital Markets: A Review of Theory and Empirical Work. The Journal of Finance. Retrieved from https://www.scirp.org/(S(351jmbntvnsjt1aadkp oszje))/reference/ReferencesPapers.aspx?Refere nceID $=1609628$

Fernandez-Perez, A., Gilbert, A., Indriawan, I., \& Nguyen, N. H. (2021). COVID-19 pandemic and stock market response: A culture effect. Journal of Behavioral and Experimental Finance, 29, 100454.

https://doi.org/10.1016/j.jbef.2020.100454

Griffith, R., Levell, P., \& Stroud, R. (2020). The Impact of COVID-19 on Share Prices in the UK. Fiscal Studies, 41(2), 363-369. https://doi.org/10.1111/1475-5890.12226

Hamza, E., Naman, J., Sana, S., \& Tanaz, B. (2020). A comparative study: impact of pandemic on pharmaceutical sectors across the globe. International Journal of Engineering Applied Sciences and Technology, 5(8), 128-132.

He, P., Sun, Y., Zhang, Y., \& Li, T. (2020). COVID-19's Impact on Stock Prices Across Different Sectors-An Event Study Based on the Chinese Stock Market. Emerging Markets Finance and Trade, 56(10), 2198-2212. https://doi.org/10.1080/1540496X.2020.178586 5

Hillier, D., Newton-lewis, T., Nair, R., \& Larsen, C. (2020). Initial COVID-19 responses in Bangladesh, Kenya, Pakistan, Sierra Leone and Uganda: Documentation and learning from March to May 2020 COVID-19 Series: Synthesis Report. Oxford Policy Management Limited. https://reliefweb.int/sites/reliefweb.int/

32 This work is licensed under a Creative Commons Attribution 4.0 International License. 
files/resources/COVID-19-Synthesis-report-

Exec-Sum-Final.pdf

Höhler, J., \& Lansink, A. O. (2020). Measuring the impact of COVID - 19 on stock prices and profits in the food supply chain. Wiley Agribusiness an International Journal, (November). https://doi.org/10.1002/agr.21678

Hutauruk, M. R. (2020). The impact before and after pandemic COVID-19 phenomenon on the IDX composite. Advanced Journal of Banking and Taxation, 1(1), 1-11.

Ibrahim, I., \& Kamaludin, K. (2020). Volatility: Evidence from the Asia-Pacific Developed and Developing Markets. Economies, 105(8), 1-22.

Machmuddah, Z., Utomo, S. D., Suhartono, E., Ali, S., \& Ali Ghulam, W. (2020). Stock market reaction to COVID-19: Evidence in customer goods sector with the implication for open innovation. Journal of Open Innovation: Technology, Market, and Complexity, 6(4), 99. https://doi.org/10.3390/joitmc6040099

Malini, H. (2020). Behaviour of Stock Returns During COVID-19 Pandemic: Evidence from Six Selected Stock Market in the World. Jurnal Ekonomi Indonesia, 9(3), 247-263.

Miati, N. L. P. M. \& Pertama, I. G. A. W. (2020). Analysis of market reactions before and after the announcement of the COVID-19 virus pandemic. International Journal of Environmental, Sustainability and Social Sciences, 21(1), 1-9. Retrieved from http://mpoc.org.my/malaysian-palm-oilindustry/

Muth, J. F. (1961). Rational expectations and the theory of price movements. Econometrica: Journal of the Econometric Society, 315-335. https://www.jstor.org/stable/1909635

Phuong, L. C. M. (2021). The Impact of COVID-19 on Stock Price: An Application of Event Study
Method in Vietnam. Journal of Asian Finance Economics and Business, 8(5), 523-531. https://doi.org/10.13106/jafeb.2021.vol8.no5.05 23

Pinches, G. E., \& Kinney, W. R. (1971). The measurement of the volatility of common stock prices. The Journal of Finance, 26(1), 119-125.

Polemis, M. \& Soursou, S. (2020). Assessing the Impact of the COVID-19 Pandemic on the Greek Energy Firms: An Event Study Analysis. Energy Research Letters, 1(3), 1-4.

Rajamohan, S., Sathish, A., \& Rahman, A. (2020). impact of COVID-19 on stock prices of NSE in automobile sector. Int. J. Adv. Multidiscip. Res, 5(6), 45-55. https://doi.org/10.22192/ijamr

Ramelli, S., \& Wagner, A. F. (2020). Feverish Stock Price Reactions to COVID-19*. The Review of Corporate Finance Studies, 9(3), 622-655. https://doi.org/10.1093/rcfs/cfaa012

Sharma, A., \& Kumar, A. (2019). A review paper on behavioral finance: study of emerging trends. Qualitative Research in Financial Markets, 12(2), 137-157. https://doi.org/10.1108/QRFM06-2017-0050

Wachter, J. (2020). Rare Events and Financial Markets. National Bureau of Economic Research. https://www.nber.org/reporter/2020n umber1/rare-events-and-financial-markets

WHO. (2021). WHO.INT. Retrieved May 21, 2021 , from corona virus interactive timeline website: https://www.who.int/emergencies/diseases/nove 1- coronavirus- 2019/interactive- timeline?gclid =CjwKCAjwtJ2FBhAuEiwAIKu19qcQGpjgzB gYEfH9y7ydi- KYWS2AsSHDWwTv80OUHa qLmewS0aLONhoCulIQAvD_BwE\#event-42

Yuliani, Y., Isnurhadi, I., \& Jie, F. (2017). Risk perception and psychological behavior of investors in emerging market: Indonesian Stock Exchange. Investment Management and

33 This work is licensed under a Creative Commons Attribution 4.0 International License. 
East African Journal of Business and Economics, Volume 5, Issue 1, 2022

Article DOI: https://doi.org/10.37284/eajbe.5.1.531

Financial Innovations, 14(2), 347-358.

https://doi.org/10.21511/imfi.14(2-2).2017.06

Yunus, M., \& Uslu, H. (2020). Effects of Covid-19 outbreak on Turkish stock market: a sectorallevel analysis. Hitit Üniversitesi Sosyal Bilimler Enstitüsü Dergisi, 56-68.

Zhang, X. (2018). The role of investor sentiment in stock market (Doctoral dissertation). Deakin University.

34 | This work is licensed under a Creative Commons Attribution 4.0 International License. 